\title{
Global regulatory agility during covid-19 and other health emergencies
}

\author{
Enhanced collaboration among authorities is key to ensuring timely access to high quality health \\ products worldwide
}

\author{
Tippi K Mak consultant ${ }^{12}{ }^{3}$, John CW Lim executive director and policy core lead ${ }^{12}$, Prapassorn \\ Thanaphollert consultant ${ }^{4}$, Gugu N Mahlangu director general ${ }^{5}$, Emer Cooke director of regulation \\ and prequalification ${ }^{6}$, Murray M Lumpkin deputy director of integrated development and lead for \\ global regulatory systems initiatives ${ }^{7}$
}

\begin{abstract}
${ }^{1}$ Centre of Regulatory Excellence, Duke-NUS Medical School, Singapore; ${ }^{2}$ SingHealth Duke-NUS Global Health Institute, Singapore; ${ }^{3}$ Vaccine and Infectious Disease Organization-International Vaccine Centre, University of Saskatchewan, Canada; ${ }^{4}$ Food and Drug Administration Thailand, Bangkok, Thailand; ${ }^{5}$ Medicines Control Authority of Zimbabwe, Harare, Zimbabwe; ${ }^{6}$ Access to Medicines and Health Products Division, World Health Organization, Geneva, Switzerland; ${ }^{7}$ Bill \& Melinda Gates Foundation, Seattle, USA
\end{abstract}

To manage the covid-19 pandemic effectively, we must have confidence in our diagnostics and medical interventions. They must be evaluated with the latest evidence on benefits carefully weighed against contextual risks, followed by prompt updates on their quality, safety, efficacy, and performance as further data become available. The job of regulators is to ensure that these products are part of the solution and not part of the problem.

Given the extreme unmet medical need, weighed against the heightened risk of covid-19, regulators recognise that affected communities generally have a greater risk tolerance and are more open to medical interventions based on fewer initial clinical data. Such "regulatory agility" in a time of complex, rapidly evolving science is an essential component of every health system's effective emergency response. Each regulatory authority should now examine if its emergency regulatory mechanisms are fit for purpose and how they can benefit from wider international regulatory experience.

Globally, regulatory authority capacity for health products varies widely. Core responsibilities include scientific assessments, clinical trial and marketing authorisation, assurance of quality manufacturing, and post-marketing vigilance. About $75 \%$ of regulatory authorities are unable to perform all core functions consistently well and depend often on better resourced authorities. ${ }^{12}$ Lack of regulatory capacity and expertise routinely compromises timely access to high quality health products and is an under-recognised problem in weak health systems. ${ }^{3}$

Especially in emergencies, better resourced regulatory authorities must remove barriers to offering timely support and sharing their full documents-such as scientific assessments and inspection reports-with less resourced authorities to support and inform their decision making. Where possible, they should also include resource constrained authorities early in key discussions on product development, clinical trials, and marketing authorisation to tackle different populations' needs and facilitate reliance on such work.

Several authorities have mechanisms for authorisation of diagnostics and medical interventions in emergencies. For example, the European Medicines Agency (EMA) can provide conditional marketing authorisation and the US Food and Drug Administration has a well established emergency use authorisation process, both of which can be quickly modified as more data become available during the emergency. ${ }^{45}$

Although many less resourced authorities do not have such specific procedures, valuable lessons were learnt from the vaccine trials during the Ebola epidemics from 2014 to 2016. The World Health Organization and the regional African Vaccine Regulatory Forum coordinated extensive international regulatory cooperation. ${ }^{6}$ Key joint meetings with ethics committees and regulators from affected countries, with experts from more resourced agencies, accelerated authorisations of clinical trials. With the support of WHO, this group of regulators later worked together on assessments for rapid marketing authorisation of an Ebola vaccine in the affected countries, after EMA's favourable scientific opinion.

WHO continues to tackle such gaps in regulatory agility, recognising that "any country could find itself involved in a public health emergency and having to put emergency regulatory processes in place in the heat of the moment, which only adds to the difficulties in an already difficult situation."7 The WHO 
prequalification programme has emergency use listing (EUL) processes for diagnostics, therapeutics, and vaccines, which provide accelerated product assessments against international standards of quality, safety, and efficacy in public health emergencies. ${ }^{8}$ Countries lacking emergency regulatory processes can rely on the EUL mechanism or the work of other trusted agencies to inform their regulatory decisions and reduce delays and duplication of effort, provided they receive the same version of the product reviewed by the reference authority or WHO.

Moreover, multilateral initiatives, such as the WHO collaborative registration procedure and other global and regional regulatory forums, can facilitate scientific discussions and promote reliance based cooperation to ensure regulatory authorities remain synchronised for timely decisions on COVID-19 health products. ${ }^{9}$

Covid-19 is an unprecedented challenge, testing our health systems and institutional responses. Regulatory authorities play a critical role and must be empowered by governments to engage in effective, agile regulation during a health emergency. Such agile approaches must be implemented now and be "interactive, flexible, and fast-but contextually rigorous" ${ }^{10}$ to ensure that we have reliable covid-19 diagnostics and high quality medical interventions for every country.

The authors alone are responsible for the views expressed in this article and they do not necessarily represent the views, decisions, or policies of the institutions with which they are affiliated.

Provenance and peer review: Not commissioned; externally peer reviewed.
Competing interests: The BMJ has judged that there are no disqualifying financial ties to commercial companies. The authors declare no other interests. The BMJ policy on financial interests is here: www.bmj.com/sites/default/files/attachments/ resources/2016/03/16-current-bmj-education-coi-form.pdf.

Khadem A. Building regulatory capacity in countries to improve the regulation of health products. 2018. www.who.int/medicines/technical_briefing/tbs/TBS2018_RSS_Capacity _ Building_CRSgroup.pdf.

2 National Academy of Sciences. Regulating medicines in a globalized world: the need for increased reliance among regulators. National Academies Press. 2019. www.nap.edu/ catalog/25594/regulating-medicines-in-a-globalized-world-the-need-for-increased.

3 WHO. Development of the roadmap on access to medicines and vaccines 2019-2023. 2020. https://apps.who.int/iris/bitstream/handle/10665/330145/9789241517034-eng.pdf.

4 European Medicines Agency. Conditional marketing authorisation: report on ten years of experience at the European Medicines Agency. www.ema.europa.eu/en/documents/report/ conditional-marketing-authorisation-report-ten-years-experience-european-medicinesagency_en.pdf.

5 US Food and Drug Administration. Emergency use authorization. www.fda.gov/emergencypreparedness-and-response/mcm-legal-regulatory-and-policy-framework/emergency-useauthorization.

6 Akanmori B, Mukanga D, Bellah A, Traore T, Ward M, Mihigo R. The role of the African Vaccine Regulatory Forum (AVAREF) in the accelerated clinical evaluation of Ebola vaccine candidates during the large west Africa epidemic. Journal of Immunological vaccine candidates during the large west Africa epidemic. Joum
Sciences. 2018;2:5-79. 10.29245/2578-3009/2018/si.1111.

7 WHO. Meeting report: WHO informal consultation on options to improve regulatory preparedness to address public health emergencies. 2017. www.who.int/blueprint/about/ r_d_blueprint_plan_of_action.pdf.

8 WHO. Emergency use listing procedure. www.who.int/medicines/publications/ EULprocedure.pdf.

9 Lim JCW. Strengthening health products regulatory systems to enhance access to quality health products in the Asia-Pacific. Ther Innov Regul Sci 2018;52:751-4. 10.1177/2168479018769285 29714589

10 Kieny MP, Rägo L. Regulatory policy for research and development of vaccines for public health emergencies. Expert Rev Vaccines 2016;15:1075-7. 10.1080/14760584.2016.1188695 27181597

Published by the BMJ Publishing Group Limited. For permission to use (where not already granted under a licence) please go to http://group.bmj.com/group/rights-licensing/ permissions 